\title{
Uncertainty and risk in climate projections for the 21st century: comparing mitigation to non-intervention scenarios
}

\author{
Lorenzo Tomassini • Reto Knutti • Gian-Kasper Plattner • Detlef P. van Vuuren • \\ Thomas F. Stocker · Richard B. Howarth • Mark E. Borsuk
}

Received: 24 June 2008 / Accepted: 30 October 2009 / Published online: 9 January 2010

(C) Springer Science+Business Media B.V. 2009

\begin{abstract}
Probabilistic climate projections based on two SRES scenarios, an IMAGE reference scenario and five IMAGE mitigation scenarios (all of them multi-gas scenarios) using the Bern2.5D climate model are calculated. Probability distributions of climate model parameters that are constrained by observations are employed as input for the climate model. The sensitivity of the resulting distributions with respect to prior assumptions on climate sensitivity is then assessed. Due to system inertia, prior assumptions on climate sensitivity play a minor role in the case of temperature projections for the first half of the 21 st century, but these assumptions have a considerable influence on the distributions of the projected temperature increase in
\end{abstract}

\section{Tomassini}

Swiss Federal Institute of Aquatic Science and Technology, Duebendorf, Switzerland

L. Tomassini · G.-K. Plattner

Environmental Physics, Institute of Biogeochemistry and Pollutant Dynamics,

ETH Zurich, Zurich, Switzerland

L. Tomassini $(\bowtie)$

Max Planck Institute for Meteorology, Bundesstrasse 53, 20146 Hamburg, Germany

e-mail: lorenzo.tomassini@zmaw.de

\section{R. Knutti}

Institute of Atmospheric and Climate Science, ETH Zurich, Zurich, Switzerland

G.-K. Plattner · T. F. Stocker

Climate and Environmental Physics, Physics Institute, University of Bern, Bern, Switzerland

D. P. van Vuuren

Netherlands Environmental Assessment Agency, Bilthoven, The Netherlands

R. B. Howarth

Environmental Studies Program, Dartmouth College, Hanover, NH, USA

M. E. Borsuk

Thayer School of Engineering, Dartmouth College, Hanover, NH, USA 
the year 2100. Upper and lower probabilities for exceeding $2^{\circ} \mathrm{C}$ by the year 2100 are calculated for the different scenarios. Only the most stringent mitigation measures lead to low probabilities for exceeding the $2^{\circ} \mathrm{C}$ threshold. This finding is robust with respect to our prior assumptions on climate sensitivity. Further, probability distributions of total present-value damages over the period 2000-2100 for the different scenarios are calculated assuming a wide range of damage cost functions, and the sensitivity of these distributions with respect to the assumed discount rate is investigated. Absolute values of damage costs depend heavily on the chosen damage cost function and discount rate. Nevertheless, some robust conclusions are possible.

\section{Introduction}

There are by now many studies on estimation of uncertainty of climate system properties and model parameters (e.g. Knutti et al. 2002, 2003; Murphy et al. 2004; Stainforth et al. 2005; Forest et al. 2006) but still only few on probabilistic climate projections. Moreover, most of these studies focus on so-called non-intervention scenarios (Wigley and Raper 2001; Stott and Kettleborough 2002; Knutti et al. 2002; Tebaldi et al. 2005) or idealized stabilization profiles (Meinshausen 2005; Knutti et al. 2005). The most prominent of those non-intervention scenarios are the SRES scenarios (Nakicenovic et al. 2000) developed for the Intergovernmental Panel on Climate Change (IPCC) Third Assessment Report (IPCC 2001) and also used for the IPCC Fourth Assessment Report (IPCC 2007).

While idealized scenarios (Knutti et al. 2005) are useful to study processes and compare methods, realistic scenarios are preferred for decision making, because they are based on a more consistent set of assumptions and scenario outcomes concerning, e.g., relations between drivers and emissions and across different gases. This makes it possible to compare the effects of policy measures with scenario assumptions. Moreover, it permits transient 21st century projections and mitigation cost estimates for specific stabilization scenarios.

Developing multi-gas mitigation scenarios has become a main focus of recent mitigation research (Weyant et al. 2006). It is estimated that including other greenhouse gases as part of the mitigation strategy may lead to a reduction of mitigation costs of up to $30-40 \%$ compared to $\mathrm{CO}_{2}$-only strategies with the same radiative forcing target (van Vuuren et al. 2006).

Probabilistic climate projections are important as a basis for decision making as they allow for an effective method in communicating and considering uncertainty. This goes beyond the traditional approach of merely computing an expected outcome and a best action based on this outcome. In this conventional decision theoretical framework, the optimum is the alternative that maximizes the expected value of an intertemporal objective function (Webster 2003). However, this rests on the assumption that we can predict the future and neglects the fact that some of the underlying premises of what we know about the future may be (partially) wrong. In terms of the models' ability to represent climate processes, problems can arise from a variety of sources: from uncertainties and inadequacies in the way models attempt to represent the climate system, arising from features such as coarse resolution, simplified parameterizations, scientific uncertainty about the feedbacks between processes, and so forth. These problems are compounded by a scarcity of data that 
can act to constrain many of the climate processes we are most interested in, and such data issues are particularly acute when we attempt to consider pre-industrial climates. A further uncertainty of entirely different nature is due to the unknown future social and economic development of the world (Webster 2003).

In the absence of reliable probabilistic inferences, strategies focussing on resilience and vulnerability reduction become preferable to more traditional risk analysis and optimization approaches. Alternative policies should be systematically and analytically evaluated against a wide range of plausible scenarios (Camerer and Weber 1992). Only by seeking strategies that are robust against a wide range of plausible climate-change futures can a consensus among the multiple actors within society on political actions be achieved (Lempert and Schlesinger 2000). Hallegate (2009) discusses specific decision-making frameworks of this kind: noregret strategies, reversible strategies, safety margin strategies, and strategies that reduce decision-making time horizons. A detailed case study on robust adaptation strategies in the water management sector is presented in Dessai and Hulme (2007).

In this paper, we present probabilistic climate projections based on a wide range of multi-gas, non-intervention as well as mitigation, scenarios using an Earth System Model of intermediate complexity. The ensemble of model parameters that are propagated through the climate model is constrained by past observations of global annual surface mean temperature and change in world ocean heat content.

A special focus of this work is the robustness of statements concerning climate change impacts with respect to prior assumptions on climate sensitivity. In 1996, the European Union formulated a target of a maximum $2^{\circ} \mathrm{C}$ rise in global average temperature. This target has since been reaffirmed by the EU on a number of occasions (e.g. Commission of the European Communities 2007). We investigate the sensitivity of the probability of exceeding $2^{\circ} \mathrm{C}$ by the year 2100 with respect to prior assumptions on climate sensitivity and find this sensitivity to be of relatively minor importance.

The structure of the present paper is as follows. In Section 2 the IMAGE reference and mitigation scenarios are described. Section 3 introduces the Bern2.5D climate model that is used for the global mean temperature projections. Section 4 describes the calculation of the multi-gas forcing from the emissions defined by the scenarios. This forcing is then used as input to the climate model. Section 5 is on statistical methods. The ensemble of climate model parameters that is used for the climate projections is described as well as the framework for the ensuing sensitivity studies.

Section 6 contains the results: probabilistic climate projections for the different scenarios, an assessment of the influence of prior assumptions on the projections, and a sensitivity study of damage costs for the various scenarios. Discussions and conclusions are presented in Section 7.

\section{IMAGE scenarios}

Most mitigation scenarios published today only consider reducing energy-related $\mathrm{CO}_{2}$ emissions. Only recently, emission modelers have started to focus on longterm multigas stabilization scenarios (for an overview, see Weyant et al. 2006). As one of the teams involved in these activities, van Vuuren et al. $(2006,2007)$ developed different sets of multi-gas mitigation scenarios that aim to stabilize radiative 
forcing of greenhouse gases. Although the two sets are based on slightly different assumptions with respect to mitigation potential and reference scenario emissions (i.e. emissions without any climate policy), they are sufficiently comparable to be combined for the purpose of this paper into a large set of scenarios that cover a wide-range of stabilization levels.

The scenarios were developed using the IMAGE 2.3 Integrated Assessment model (MNP 2006)—including the TIMER energy model (van Vuuren 2007)—and the climate-policy model FAIR 2.0 (den Elzen and Lucas 2003). The IMAGE model is an Integrated Assessment model, consisting of a set of linked and integrated models that together describe important elements of the long-term dynamics of global environmental change, such as agriculture and energy use, climate change, land-use change and environmental impacts.

In total, six different scenarios have been selected from the IMAGE set: a reference scenario and five multi-gas mitigation scenarios. Three of these scenarios stabilize radiative forcing at $5.3 \mathrm{~W} / \mathrm{m}^{2}, 4.5 \mathrm{~W} / \mathrm{m}^{2}, 3.7 \mathrm{~W} / \mathrm{m}^{2}$ by 2100 . Two other scenarios are overshoot scenarios that lead to $2.9 \mathrm{~W} / \mathrm{m}^{2}$ and $2.6 \mathrm{~W} / \mathrm{m}^{2}$ in the year 2100 , having peaked at $3.2 \mathrm{~W} / \mathrm{m}^{2}$ and $2.9 \mathrm{~W} / \mathrm{m}^{2}$, respectively. The last scenario was only achievable by adding the option of bio-energy and carbon storage to the model. All scenarios assume full participation of countries in emission reductions from 2015 onwards. Note, however, that the actual forcing levels presented in this paper corresponding to the different scenarios differ slightly from the ones reported by van Vuuren et al. $(2006,2007)$ because we calculated the forcings here based on the Bern2.5CC model and Joos et al. (2001) instead of the IMAGE model (see Section 4). As a result, also the effective stabilization levels are not precisely the ones suggested by the names of the scenarios. Figure 1 (left panel) shows the total forcing for the years 2000 to 2100 of all the scenarios presented in this paper. Table 1 summarizes the total forcing of the different scenarios in the year 2100 .

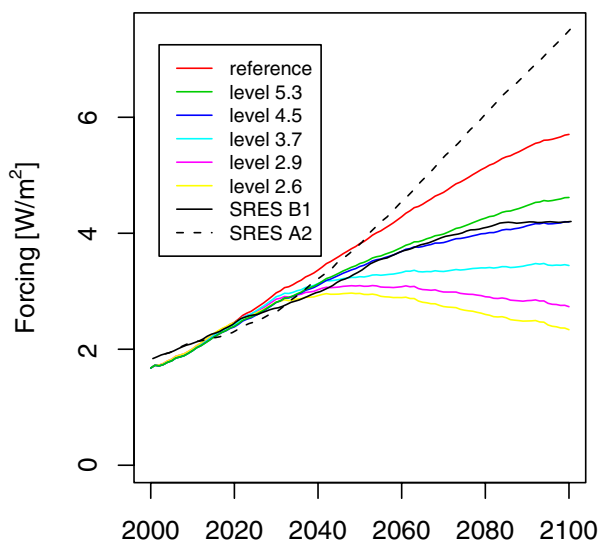

year

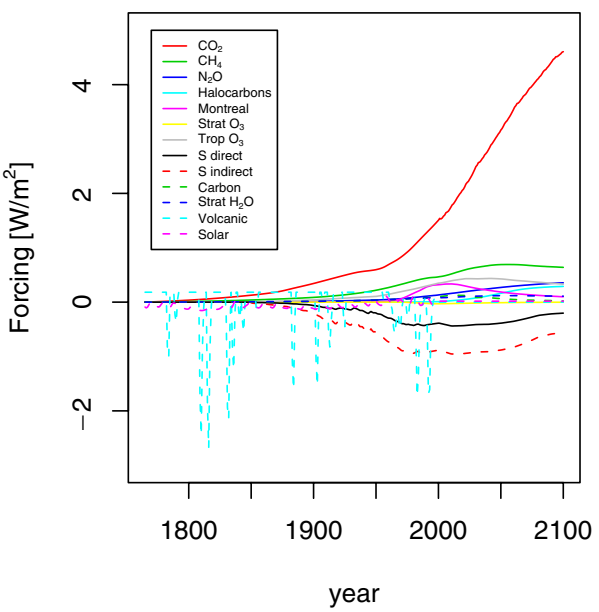

Fig. 1 Left panel: total radiative forcing for all scenarios for the years 2000 to 2100. Right panel: the different forcing components of the IMAGE reference scenario. Note that both panels include the direct forcing only, and that the climate feedback on the carbon cycle is considered separately 
Table 1 Value of total forcing at year 2100 for all scenarios

\begin{tabular}{ll}
\hline Scenario & Forcing at year $2100\left[\mathrm{Wm}^{-2}\right]$ \\
\hline Reference & 5.7 \\
Level $5.3 \mathrm{Wm}^{-2}$ & 4.6 \\
Level $4.5 \mathrm{Wm}^{-2}$ & 4.2 \\
Level $3.7 \mathrm{Wm}^{-2}$ & 3.4 \\
Level $2.9 \mathrm{Wm}^{-2}$ & 2.7 \\
Level $2.6 \mathrm{Wm}^{-2}$ & 2.3 \\
SRES B1 & 4.2 \\
SRES A2 & 7.5 \\
\hline
\end{tabular}

The IMAGE scenarios were defined by first constructing a reference scenario that describes development of emissions without climate policy. Next, global emission profiles were devised that lead to the stabilization (or peak) of greenhouse gases at different forcing levels. On the basis of mitigation potential and associated costs, the global emission reduction objective was distributed among different gases and sources. Finally, the resulting emission profiles were rerun in the overall IMAGE framework to develop consistent energy, land use and emission scenarios.

The reference scenario, an updated implementation of the SRES B2 scenario, should be regarded as a medium emission scenario, on the basis of median assumptions for population, economic growth, energy use and land use. The stabilization scenarios were developed on the basis of a set of rules: 1) they needed to comply with the stabilization target, 2) reductions were required to be consistent with the identified emission potential in different sectors, 3) for most levels, concentrations were not allowed to overshoot the target level (this requirement was relaxed for the lowest levels) and 4) maximum reduction rates of $3 \%$ per year were allowed to account for system inertia (depending on the stabilization levels). More information can be found in van Vuuren et al. (2006) and den Elzen et al. (2007).

The resulting stabilization scenarios form a consistent representation of reduction scenarios across the different gasses. As they were partly developed within the EMF21 modeling exercise (Weyant et al. 2006), they are consistent with current literature on this issue.

In order to set the IMAGE scenarios in relation to the widely used SRES (Special Report on Emission Scenarios) family, we also present probabilistic climate projections based on the SRES A2 and SRES B1 scenarios (Section 6.1). These two non-intervention scenarios basically span the full range of the SRES emission scenario family (see Section 6.1 for the economic and demographic story lines of the two scenarios).

\section{Climate model}

For our climate projections we use the Bern2.5D climate model, an Earth System model of intermediate complexity. It consists of a zonally averaged dynamic ocean model (Stocker and Wright 1991; Wright and Stocker 1991) resolving the Atlantic, Pacific, Indian and Southern oceans, coupled to a zonally and vertically averaged energy- and moisture-balance model of the atmosphere (Stocker et al. 1992; Schmittner and Stocker 1999). 
The additional radiative forcing at the top of the atmosphere is specified as

$$
\Delta F_{\text {toa }}(t)=\Delta F_{\text {dir }}(t)+\mu \cdot \Delta T_{\text {atm }}(t)
$$

where $\Delta F_{d i r}$ is the direct radiative forcing reconstructed over the industrial period. Feedback processes which increase the climate sensitivity $S$ are represented by the feedback term $\mu \cdot \Delta T_{\text {atm }}(t)$, where $\Delta T_{\text {atm }}$ is the time-dependent atmospheric globalmean temperature increase and $\mu$ is a constant, which is prescribed to lead to different climate sensitivities for the same radiative forcing.

The climate sensitivity $S$ is defined as the equilibrium global mean near-surface warming for a doubling of preindustrial atmospheric carbon dioxide, equivalent to a radiative forcing of about $3.71 \mathrm{Wm}^{-2}$ (Myhre et al. 1998).

We used a model version with a lateral ocean mixing scheme and depth independent vertical ocean diffusivity $K_{v}$ (Wright and Stocker 1991). Knutti et al. (2000) investigated the effect of different ocean mixing parametrizations. For the present study, the relevance of other mixing schemes is small and was subsequently neglected (Knutti et al. 2002).

The net heat uptake by the ocean, $F$, is given by Stocker et al. (1992) as

$$
F=(1-\kappa) Q^{\text {short }}-\sigma e_{O} T^{4}+\sigma e_{A} T_{A}^{4}-D\left(T-T_{A}\right)-E,
$$

where $E$ is the temperature-dependent evaporation, $T_{A}$ is the atmospheric temperature, $T$ the ocean surface temperature, $Q^{\text {short }}$ the net incoming shortwave radiation, $\kappa$ a constant atmospheric absorptivity, $e_{A}$ and $e_{O}$ are atmospheric and oceanic emissivities, $\sigma$ is the Boltzmann constant, $c_{E}$ the bulk coefficient of evaporation, and $D$ a constant transfer coefficient for sensible heat (Haney 1971).

The forcing of the climate model as calculated from the emissions defined by the scenarios is described in the next section.

\section{Forcing}

The following paragraphs of this section describe the radiative forcing that was used for the simulations with the Bern2.5D climate model. The right panel of Fig. 1 shows the different forcing components for the IMAGE reference scenario as an example.

\subsection{Non- $\mathrm{CO}_{2}$ atmospheric components}

The radiative forcings from non- $\mathrm{CO}_{2}$ greenhouse gases and other radiative forcing agents $\left(\mathrm{CH}_{4}, \mathrm{~N}_{2} \mathrm{O}, \mathrm{SF}_{6}, 28\right.$ halocarbons including those controlled by the Montreal Protocol, stratospheric $\mathrm{O}_{3}$, the direct forcing of black and organic carbon, stratospheric $\mathrm{H}_{2} \mathrm{O}$ due to $\mathrm{CH}_{4}$ changes, and the direct and indirect effects of aerosols) for the historic period are calculated from emissions and concentrations using simplified expressions according to IPCC Third Assessment Report (IPCC 2001) as described in detail by Joos et al. (2001). For the IMAGE baseline and mitigation scenarios, the simplified expressions and parameters of the radiative forcing calculations have been updated based on the recent IPCC Fourth Assessment Report (IPCC 2007; Forster et al. 2007). These updates include, e.g., updated lifetimes and radiative efficiencies for some of the halocarbons and updated year-2000 radiative 
forcings for some groups of radiative agents, used to scale the forcing over the entire period. In addition, for SOx, updated historic emission data were used (Stern 2005).

The sum of all non- $\mathrm{CO}_{2}$ radiative forcings for each individual scenario is prescribed as external input to the Bern2.5D model, i.e. for non- $\mathrm{CO}_{2}$ components the respective radiative forcing was computed externally and added to the radiative forcing input of the climate model.

\section{2 $\mathrm{CO}_{2}$ radiative forcing}

The atmospheric $\mathrm{CO}_{2}$ concentration, and thus $\mathrm{CO}_{2}$ radiative forcing, are determined by the Bern2.5CC model (Joos et al. 2001; Plattner et al. 2001). This version of the Bern2.5D model includes an interactive carbon cycle module which allows to project atmospheric $\mathrm{CO}_{2}$ from prescribed carbon emissions. For the historic period until year 2000, atmospheric $\mathrm{CO}_{2}$ concentrations are prescribed by a spline through ice core data from Siegenthaler et al. (2005) and Etheridge et al. (1996), and direct atmospheric measurements from Mauna Loa and South Pole from Keeling and Whorf (2005). From year 2000 on until year 2100, $\mathrm{CO}_{2}$ emissions from the IMAGE emission scenarios are prescribed, and atmospheric $\mathrm{CO}_{2}$ concentrations are interactively calculated in the model. The $\mathrm{CO}_{2}$ radiative forcing is then calculated from atmospheric $\mathrm{CO}_{2}$ according to IPCC Third Assessment Report (IPCC 2001) as

$$
\mathrm{RF}_{\mathrm{CO}_{2}}(t)=5.35 \frac{\mathrm{W}}{\mathrm{m}^{2}} \cdot \log \left(\frac{\mathrm{CO}_{2}(t)}{\mathrm{CO}_{2}(0)}\right)
$$

where $\mathrm{CO}_{2}(0)$ denotes the preindustrial $\mathrm{CO}_{2}$-concentration, here taken to be $277.8 \mathrm{ppm}$ in year 1765 .

The calculations with the Bern2.5CC model are performed with constant climate with respect to the carbon cycle, and thus the projected atmospheric $\mathrm{CO}_{2}$ and $\mathrm{CO}_{2}$ radiative forcing do not account for climate-carbon cycle feedbacks (which tend to increase atmospheric $\mathrm{CO}_{2}$ and radiative forcing compared to the constant climate case; Joos et al. 1999; Friedlingstein et al. 2006; Plattner et al. 2008). Instead these climate-carbon cycle feedbacks are parameterized in the Bern2.5D climate model and included in the uncertainty analysis (Knutti et al. 2003; see Section 5.1).

\subsection{Solar forcing}

For the SRES scenarios, historic solar forcing was taken from Crowley (2000; based on Bard et al. 2000). For the IMAGE scenarios, the updated solar forcing time series from Wang et al. (2005) was used which shows a smaller amplitude of variability compared to the Crowley time series.

For the IMAGE scenarios, solar irradiance has been converted to radiative forcing using

$$
\mathrm{RF}_{\text {solar }}(t)=\frac{\left(\operatorname{Irr}(t)-1366 \frac{\mathrm{W}}{\mathrm{m}^{2}}\right)}{4} \cdot 0.7
$$

After 1998 the solar forcing is assumed to be constant and the mean from the years 1977 to 1998 is prescribed. 
4.4 Volcanic forcing

For the simulations in Tomassini et al. (2007) the volcanic forcing of Ammann et al. (2003) was prescribed for the historic period. In the IMAGE scenarios, the Crowley (2000) volcanic forcing was used and scaled to mean zero forcing for the period 1000 to 1998. After year 2000, the volcanic forcing is set to zero. This scaling to the longterm mean excludes a net positive forcing from volcanoes after the year 2000.

\section{Statistical methods}

For the probabilistic climate projections, we use a multidimensional probability distribution for the parameters of the Bern2.5D climate model and propagate it through the model. This results in probability distributions for the projected rise in surface temperature.

The probability distribution of the parameters was derived using a Bayesian formalism (Tomassini et al. 2007). That is, for a vector of parameters $\theta=\left(\theta_{1}, \ldots, \theta_{p}\right)$ and observations $y=\left(y_{1}, \ldots, y_{m}\right)$, we calculated the multivariate posterior probability density of the parameters given the data according to Bayes' theorem:

$$
p(\theta \mid y) \propto \ell(y, \theta) \cdot p(\theta)
$$

where $\ell(y, \theta)$ is the likelihood function (the conditional probability density of the observations $y$ given the parameters $\theta)$ and $p(\theta)$ the prior probability density for the vector of parameters.

The observations that were used consist of global annual mean surface temperature data (Jones and Moberg 2003) from the years 1861 to 2003 and annual mean change in world ocean heat content down to 700 meters depth (Levitus et al. 2005) from the years 1955 to 2003. Both data sets are publicly available (see the URLs in the reference section). A discussion of the effect of ocean heat uptake uncertainty in transient warming is given in Knutti and Tomassini (2008).

For the precise definition of the likelihood function and the technical issues regarding the estimation of the posterior probability distribution see Tomassini et al. (2007).

\subsection{Parameters and distributions}

We included 12 parameters of the Bern2.5D climate model in the Bayesian uncertainty analysis to derive the posterior distributions. The set of considered parameters consists of the climate sensitivity $S$, the vertical ocean diffusivity $K_{v}$, the transfer coefficient for sensible heat $D$ and 9 forcing scale parameters.

Climate sensitivity is the key parameter that governs the long-term temperature response of the climate system to an increase in the radiative forcing. The vertical ocean diffusivity determines the strength of mixing of heat into the deep ocean, and the forcing parameters take the uncertainty in the historical radiative forcing reconstructions into account. The transfer coefficient for sensible heat is an uncertain parameter that affects the exchange of heat between ocean and atmosphere.

The forcing parameters consist of multiplicative dimensionless factors by which the historical forcing reconstructions for the various atmospheric components were 
individually scaled. This includes a scale parameter $s_{\text {indir }}$ for the indirect aerosol forcing (Knutti et al. 2002). Greenhouse gases $\mathrm{CO}_{2}, \mathrm{CH}_{4}, \mathrm{~N}_{2} \mathrm{O}, \mathrm{SF}_{6}$ and halocarbons were combined in one group. The standard deviations of the prior distributions for the forcing scale parameters were derived from the assumption that the uncertainties given by IPCC in the Third Assessment Report (IPCC 2001) represent a range of plus or minus one standard deviation. A Gaussian prior distribution was assumed where the uncertainties are given in percent, and a log-normal distribution was used where the uncertainty is given as a factor (Knutti et al. 2003).

For climate sensitivity and the vertical ocean diffusivity, uniform prior distributions were applied in our baseline assumptions but see Section 5.2 for different prior assumptions on climate sensitivity $S$ ). The uniform prior for climate sensitivity is restricted to the interval $\left[1^{\circ} \mathrm{C}, 10^{\circ} \mathrm{C}\right]$ because the climate sensitivity $S$ of the model is controlled by the parameter $\mu$. The relation between $S$ and $\mu$ is nonlinear and approximated numerically. This approximation is only accurate on the interval $\left[1^{\circ} \mathrm{C}, 10^{\circ} \mathrm{C}\right]$. Similarly, the uniform prior for $K_{v}$ is restricted to the interval $\left[1.375 \cdot 10^{-4} \mathrm{~m}^{2} / \mathrm{s}, 15.125 \cdot 10^{-4} \mathrm{~m}^{2} / \mathrm{s}\right]$. Previous modelling studies suggest that these are reasonable ranges for this model (Knutti et al. 2003; Tomassini et al. 2007).

For the transfer coefficient of sensible heat $D$, an objectively estimated best guess value is available (Haney 1971), and a Gaussian prior was used.

For simplicity we assume a priori that all parameters are independent. Note that all prior distributions used are proper.

Figure 2 in Tomassini et al. (2007) shows all marginal prior and marginal posterior distributions for the different parameters involved.

For the climate projections, we introduce an additional parameter $\gamma$ to account for the uncertainty in the carbon cycle-climate feedback (Knutti et al. 2003). The difference in projected $\mathrm{CO}_{2}$ between model simulations with global warming and without global warming quantifies the feedback between climate change and the global carbon cycle. It is expressed here as the ratio $\gamma$ of the change in radiative forcing per degree surface warming. Radiative forcing $\mathrm{RF}_{\mathrm{CO}_{2}}\left(t, \Delta T_{2000}\right)$ from atmospheric $\mathrm{CO}_{2}$ is thus calculated for each scenario as a function of the simulated global mean surface temperature change $\Delta T_{2000}$ since year 2000 and a scenario dependent trajectory of future $\mathrm{CO}_{2}$ forcing $\mathrm{RF}_{\mathrm{CO}_{2}}\left(t, \Delta T_{2000}=0\right)$ :

$$
\mathrm{RF}_{\mathrm{CO}_{2}}\left(t, \Delta T_{2000}\right)=\mathrm{RF}_{\mathrm{CO}_{2}}\left(t, \Delta T_{2000}=0\right)+\gamma \cdot \Delta T_{2000}(t)
$$

While there are multiple processes on various timescales that operate in the carbon cycle, it has been shown that a single feedback parameter with an appropriate strength can capture the main effect up to 2100 (Knutti et al. 2003; Friedlingstein et al. 2006; Plattner et al. 2008; Gregory et al. 2009).

For the uncertain parameter $\gamma$, a normal distribution with mean $0.25 \mathrm{Wm}^{-2} / \mathrm{K}$ and a standard deviation of $0.05 \mathrm{Wm}^{-2} / \mathrm{K}$ was used (Knutti et al. 2003, Appendix $1)$. The mean is justified by simulations with the Bern $2.5 \mathrm{CC}$ model, the standard deviation was based on uncertainty estimates in IPCC (2001). These uncertainty estimates remained virtually the same in the IPCC Fourth Assessment Report.

\subsection{Classes of priors and their projections}

Following robust Bayesian practice (Berger 1984, 1994), in Tomassini et al. (2007) we introduced a non-parametric set of prior distributions for climate sensitivity that 

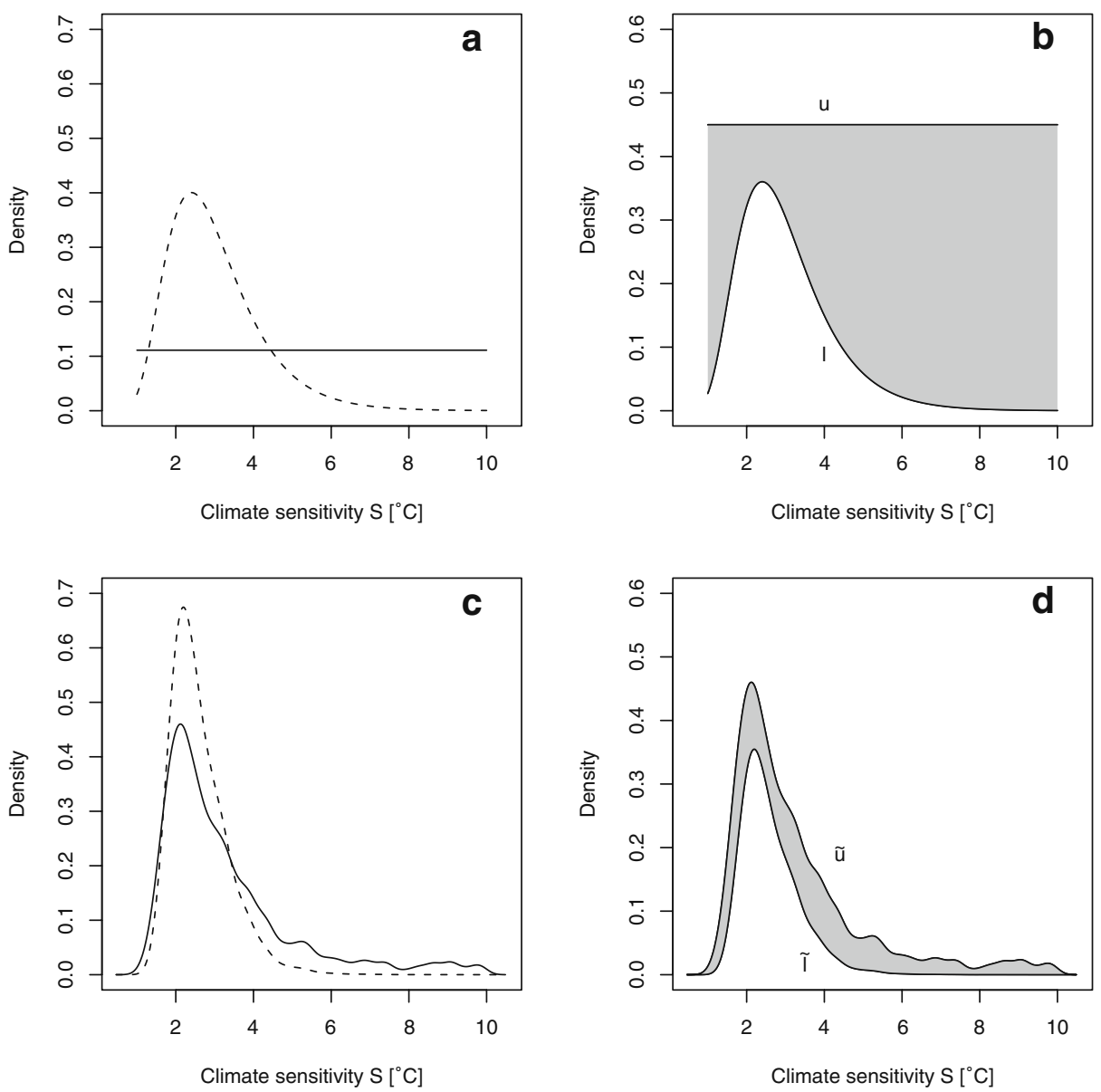

Fig. 2 a Normalized upper and lower bound of the prior density ratio class; b Prior density ratio class for climate sensitivity; c Normalized upper and lower bound of the posterior density ratio class; d Posterior density ratio class for climate sensitivity

includes the uniform distribution as well as informative priors. This entire set of prior distributions was then updated according to Bayes' theorem, which resulted in a set of posterior distributions.

We made use of the density ratio class of distributions (De Robertis and Hartigan 1981). This is defined by the set of distributions of the form

$$
B(l, u)=\left\{p \in C(\mathbb{R}) \mid p=\frac{q}{\int_{\mathbb{R}} q d \mu}, l(x) \leq q(x) \leq u(x) \forall x \in \mathbb{R}\right\},
$$

where $l$ and $u$ are specific functions, called the lower bound and the upper bound, respectively, of $B(l, u)$.

In words, for any probability density function $p$ in $B(l, u)$ there is a continuous function $q$, which is bounded by $l$ and $u$, such that $p$ is equal to $q$ times a normalizing constant (which guarantees that $p$ is normalized to 1 ). 
In Tomassini et al. (2007) the lower bound $l$ and the upper bound $u$ were chosen in such a way that $B(l, u)$ contains the uniform distribution as well as several expert priors of Morgan and Keith (1995) for climate sensitivity.

The upper bound is a rescaled density function of the uniform distribution, the lower bound a rescaled density of the log-normal distribution with mean $m=3{ }^{\circ} \mathrm{C}$ and standard deviation $s t d=1.2^{\circ} \mathrm{C}$. Expert priors for climate sensitivity often have the form of a lognormal distribution, and the value of $3{ }^{\circ} \mathrm{C}$ is a reasonable best guess value for climate sensitivity (Knutti and Hegerl 2008). The prior distributions for all the other parameters are kept fixed.

Figure 2 shows the prior and posterior set of distributions for climate sensitivity that were derived in Tomassini et al. (2007) and used in the present study.

For the climate projections, it suffices to project a sample of only the upper bound of the density ratio class through the climate model. The projected lower bound of the class can then be estimated based on the following considerations:

We call a sequence of pairs $\left(w_{i}, x_{i}\right)_{i=1, \ldots, N}$ a weighted sample for a probability density $p$, if i) $w_{i} \in \mathbb{R}, \sum_{i=1}^{N} w_{i}=1$, ii) $\left(x_{i}\right)_{i=1, \ldots, N}$ is a sample of an arbitrary probabilility density $q$, and if iii) any expectation $\mathrm{E}_{p}[\varphi]$ with respect to $p$ can be approximated by $\mathrm{E}_{p}[\varphi] \approx \sum_{i=1}^{N} w_{i} \varphi\left(x_{i}\right)$.

An analogous statement holds if the density $p$ is not normalized but still integrable. In this case the weights $w_{i}$ do not sum up to one, but to the total mass of $p$.

Weighted samples are invariant under projections in the sense that if $\left(w_{i}, x_{i}\right)_{i=1, \ldots, N}$ is a weighted sample for $p$, then $\left(w_{i}, f\left(x_{i}\right)\right)_{i=1, \ldots, N}$ is a weighted sample for the projected density $f^{*} p$ for any model function $f$ (Isaaks and Srivastava 1989, Chapter 8).

In our situation, we can choose a weighted sample for the lower bound of the density ratio class which consists of a sample of the upper bound of the class and appropriate weights $w_{i}$. This immediately gives a weighted sample for the projected lower bound from the projected sample of the upper bound.

\section{Results}

\subsection{Probabilistic climate projections}

Probabilistic climate projections were performed with the Bern2.5D climate model making use of the IMAGE reference scenario, the five corresponding IMAGE mitigation scenarios (Section 2), and SRES scenarios B1 and A2 (Nakicenovic et al. 2000). The posterior parameter sample for the climate model as derived in Tomassini et al. (2007) was used, as well as a probability distribution for the carbon cycle-climate feedback parameter $\gamma$ as described in Section 5.1. This means that we consider only the uncertainty in climate model parameters, and not uncertainty in the economic development (for a fixed scenario) or other aspects. We also neglect uncertainty due to short-term climate variability.

Figure 3 gives an overview of the probabilistic climate projections for the different scenarios. Here the posterior parameter sample of what was called the baseline case in Tomassini et al. (2007) was used. The first panel shows projected global mean temperature in the year 2050 for the IMAGE scenarios. One can see that the 

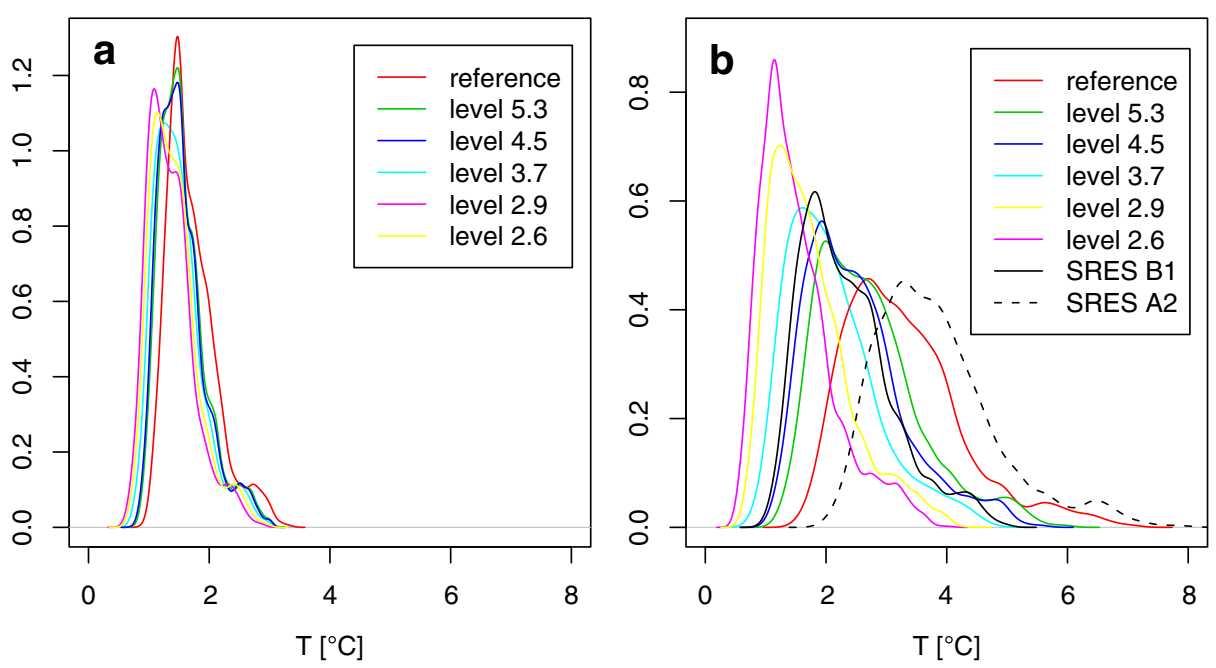

Fig. 3 a Scenario projections of global mean temperature increase in the year 2050 for the IMAGE scenarios; b Scenario projections of global mean temperature increase in the year 2100 for the IMAGE scenarios and two SRES scenarios

probability distributions differ only slightly. For the reference scenario, the mean temperature increase for the year 2050 is $1.7^{\circ} \mathrm{C}$ with a standard error of only $0.4^{\circ} \mathrm{C}$. This means that, for the considered scenario family, the temperature increase in the year 2050 is largely independent of the scenario and likely lies within the range of $\left[1.3^{\circ} \mathrm{C}, 2.2^{\circ} \mathrm{C}\right]$.

In the second panel, global mean temperature in the year 2100 is presented for the IMAGE scenarios and two SRES scenarios. Table 2 summarizes means, standard deviations, and the 0.05 and 0.95 quantiles of all the distributions for global mean temperature increase in the year 2100 .

The IMAGE scenarios are described in Section 2. Here we also consider the two SRES scenarios B1 and A2 for comparison.

The scenario A2 is at the high end of the SRES (non-intervention) scenario family developed for the IPCC Third Assessment Report (IPCC 2001). It assumes a heterogeneous world and continuously increasing global population. Economic development is primarily regionally oriented and per capita economic growth and

Table 2 Means, standard deviations, and 0.05/0.95 quantiles of global mean temperature in the year 2100 for the different scenarios

\begin{tabular}{|c|c|c|c|c|}
\hline Scenario & $\begin{array}{l}\text { Mean } \\
{\left[{ }^{\circ} \mathrm{C}\right]}\end{array}$ & $\begin{array}{l}\text { Standard } \\
\text { deviation }\left[{ }^{\circ} \mathrm{C}\right]\end{array}$ & $\begin{array}{l}\text { Quantile } \\
(0.05)\left[{ }^{\circ} \mathrm{C}\right]\end{array}$ & $\begin{array}{l}\text { Quantile } \\
(0.95)\left[{ }^{\circ} \mathrm{C}\right]\end{array}$ \\
\hline Reference & 3.29 & 0.98 & 2.03 & 5.25 \\
\hline Level $5.3 \mathrm{Wm}^{-2}$ & 2.70 & 0.86 & 1.61 & 4.47 \\
\hline Level $4.5 \mathrm{Wm}^{-2}$ & 2.49 & 0.83 & 1.44 & 4.19 \\
\hline Level $3.7 \mathrm{Wm}^{-2}$ & 2.10 & 0.74 & 1.16 & 3.64 \\
\hline Level $2.9 \mathrm{Wm}^{-2}$ & 1.73 & 0.67 & 0.90 & 3.15 \\
\hline Level $2.6 \mathrm{Wm}^{-2}$ & 1.53 & 0.63 & 0.76 & 2.88 \\
\hline SRES B1 & 2.34 & 0.76 & 1.37 & 3.87 \\
\hline SRES A2 & 3.83 & 1.01 & 2.54 & 5.9 \\
\hline
\end{tabular}


technological change are more fragmented and slower than in other storylines. Accordingly the distribution for projected global mean temperature increase shows a high mean value of $3.83{ }^{\circ} \mathrm{C}$ and a $90 \%$ confidence bound of $\left[2.54^{\circ} \mathrm{C}, 5.9^{\circ} \mathrm{C}\right]$. The probability that global mean temperature increase in the year 2100 exceeds $2{ }^{\circ} \mathrm{C}$ is 0.98 , that is, it is almost certain.

The B1 scenario describes a convergent world with a global population that peaks in mid 21st century and declines thereafter, with rapid changes in economic structures towards a service and information economy, with reductions in material intensity, and the introduction of clean and resource-efficient technologies. The emphasis is on global solutions to economic, social, and environmental sustainability, including improved equity, but without additional climate initiatives. The B1 scenario can therefore be termed a "sustainable development scenario" and is representative of the lowest scenarios in the literature that do not include explicit climate policy. The probability that global mean temperature increase in the year 2100 exceeds $2{ }^{\circ} \mathrm{C}$ is 0.6 for this scenario.

The IMAGE reference scenario has lower emissions than the A2 scenario, but still shows a substantial increase of emissions. The mean value of 2100 temperature is $3.29^{\circ} \mathrm{C}$ and the probability of exceeding the $2{ }^{\circ} \mathrm{C}$ is 0.95 (very likely). The IMAGE mitigation scenario that stabilizes the forcing at $5.3 \mathrm{Wm}^{-2}$ reduces the probability of exceeding the $2{ }^{\circ} \mathrm{C}$ target to 0.78 (still a likely exceedance). The $4.5 \mathrm{Wm}^{-2}$ scenario results in similar climate change as the $\mathrm{B} 1$ scenario: the mean value for global mean temperature increase is $2.49^{\circ} \mathrm{C}$ and the probability of exceeding the $2{ }^{\circ} \mathrm{C}$ target is 0.69 . For the scenario that stabilizes the forcing at $3.7 \mathrm{Wm}^{-2}$ this probability further declines to 0.48 (about as likely as not).

In other words, the probability distributions for global mean temperature increase in the year 2100 for the IMAGE mitigation scenarios that stabilize radiative forcing at $3.7 \mathrm{Wm}^{-2}, 4.5 \mathrm{Wm}^{-2}$, and $5.3 \mathrm{Wm}^{-2}$ are rather similar. The maximum difference in mean values is only $0.6^{\circ} \mathrm{C}$. However, these differences could become substantial when extending the time horizon to later years such as 2200 or 2300.

The picture is substantially different with the overshoot scenarios that stabilize radiative forcing at $2.9 \mathrm{Wm}^{-2}$ and $2.6 \mathrm{Wm}^{-2}$, respectively. The means of projected global temperature increase in the year 2100 are considerably lower than in the case of the other scenarios. The probability that global mean temperature increase in the year 2100 exceeds $2{ }^{\circ} \mathrm{C}$ is only 0.19 in the case of the scenario that stabilizes forcing at $2.6 \mathrm{Wm}^{-2}$, and 0.29 in the case of the scenario that stabilizes forcing at $2.9 \mathrm{Wm}^{-2}$ (in both cases unlikely).

Since the critical tails of the distributions for projected temperature increase are mainly a consequence of the tails in the propagated distribution of climate sensitivity, in the following we investigate the effect of different assumptions regarding prior distributions for climate sensitivity on the temperature projections.

\subsection{Projected prior uncertainty of climate sensitivity}

As described in Section 5.2, in Tomassini et al. (2007) we considered a nonparametric set of prior distributions for climate sensitivity and derived a corresponding set of posterior distributions (see Fig. 2). This permitted the assessment of the robustness of the parameter estimates with respect to prior assumptions on climate sensitivity. 
Similarly, we can quantify the effect of these prior assumptions on the climate projections. The right panels of Fig. 4 show the projected density ratio class, that is, a density ratio class for global mean temperature increase in the year 2100 for four different scenarios. These density ratio classes are constructed by projecting the upper bound $\tilde{u}$ and the lower bound $\tilde{l}$ of the posterior density ratio class for climate sensitivity through the climate model.

As described in Section 5.2 it suffices to perform the model simulations for the (normalized) upper bound. The projected lower bound can then be estimated using the importance sampling idea, as outlined in Section 5.2. The left panels of Fig. 4
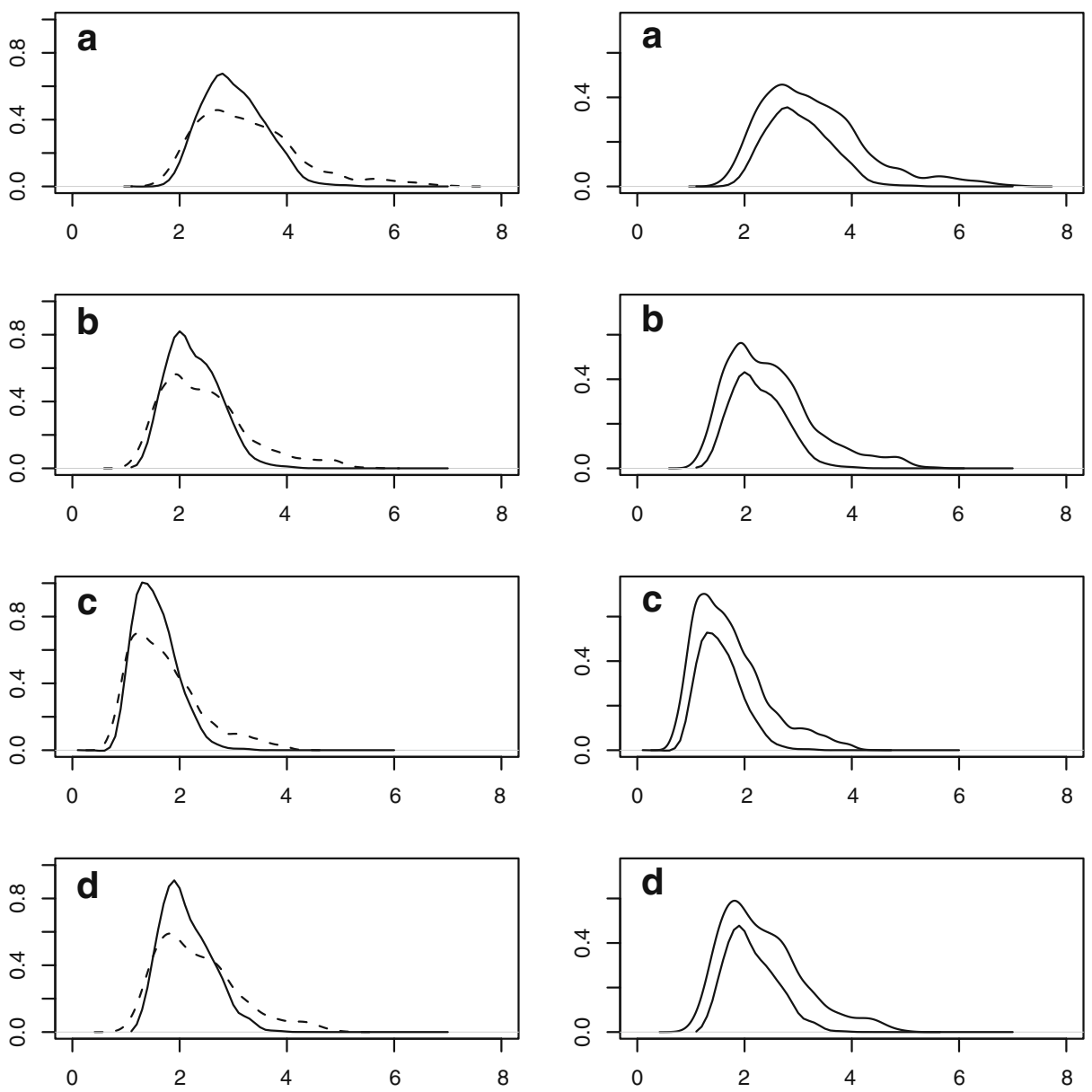

Fig. 4 Probability distributions for global mean temperature increase in the year $2100\left[{ }^{\circ} \mathrm{C}\right]$ resulting from projections of the posterior density ratio class for climate sensitivity. Left panels: normalized lower (solid line) and upper (dashed line) bounds of the density ratio class. Right panels: unnormalized lower and upper bounds. a Reference scenario; b Scenario with stabilization at $4.5 \mathrm{~W} / \mathrm{m}^{2}$; c Scenario with stabilization at $2.9 \mathrm{~W} / \mathrm{m}^{2}$; d SRES B1 scenario. Recall that the normalized upper bound of the density ratio class corresponds to a posterior resulting from a uniform prior for climate sensitivity, the normalized lower bound to a posterior resulting from a log-normal prior with mean 3 and standard deviation 1.2 
depict the normalized upper and lower bounds of the corresponding density ratio classes.

One can observe that prior assumptions on climate sensitivity have an influence on the tails of the resulting distributions for global mean surface temperature in the year 2100. To better assess the significance of this influence in a tangible decision making context, we calculate upper and lower probabilities (e.g. Wasserman and Kadane 1992) of exceeding a temperature increase of $2^{\circ} \mathrm{C}$ for the different sets of distributions (corresponding to the different scenarios).

More precisely, the maximum (minimum) of all probabilities of exceeding the $2^{\circ} \mathrm{C}$ threshold over the set of probability distributions presented in Fig. 4 are computed. The results are summarized in Table 3 and are largely in agreement with similar estimates by Meinshausen (2005) and Meinshausen et al. (2009).

The range between upper and lower probabilities, that is the influence of the prior assumptions on climate sensitivity, is largest in the case of the mitigation scenarios that stabilize radiative forcing at low levels. This is probably due to the fact that, in the case of the low level scenarios, the system is closest to realizing its equilibrium warming, so the response is more related to climate sensitivity than it would be in the situations where the response is still near-transient.

In terms of the IPCC terminology (0-10\% probability: very unlikely, $10-33 \%$ : unlikely, 66-90\%: likely, 90-100\%: very likely) the result is quite robust with respect to prior assumptions on climate sensitivity: only in the case of the most stringent mitigation scenarios considered (stabilization at $2.6 \mathrm{Wm}^{-2}$ and $2.9 \mathrm{Wm}^{-2}$ ) exceeding a temperature increase of $2^{\circ} \mathrm{C}$ is unlikely. Here, the lower bounds on probability would even imply that exceedance is very unlikely. (Note, however, that one may question whether a probability of "failure" of $20-30 \%$ would be considered acceptably low in other policy areas.).

\subsection{Pdfs for monetized damage costs}

When assessing impacts of climate change, as a first stage, global mean temperature increase with respect to preindustrial times is often used as a metric for damages. In the present work, we go one step further and present also probabilistic estimates of (monetized) damage costs for the different scenarios and different assumptions on damage costs.

Although our analysis is simple, it has the advantage of being transparent. This allows for a detailed sensitivity analysis. We consequently consider not so much

Table 3 Upper and lower probabilities of exceeding $2^{\circ} \mathrm{C}$ for different scenarios

\begin{tabular}{|c|c|c|c|c|}
\hline Scenario & $\begin{array}{l}\text { Probability of } \\
\text { exceeding } 2^{\circ} \mathrm{C}\end{array}$ & $\begin{array}{l}\text { Lower } \\
\text { prob. }\end{array}$ & $\begin{array}{l}\text { Upper } \\
\text { prob. }\end{array}$ & $\begin{array}{l}\text { IPCC } \\
\text { terminology }\end{array}$ \\
\hline Reference & 0.95 & 0.91 & 0.99 & Very likely \\
\hline Level $5.3 \mathrm{Wm}^{-2}$ & 0.78 & 0.65 & 0.88 & Likely \\
\hline Level $4.5 \mathrm{Wm}^{-2}$ & 0.67 & 0.52 & 0.79 & Likely \\
\hline Level $3.7 \mathrm{Wm}^{-2}$ & 0.48 & 0.34 & 0.65 & Likely \\
\hline Level $2.9 \mathrm{Wm}^{-2}$ & 0.29 & 0.09 & 0.39 & Unlikely \\
\hline Level $2.6 \mathrm{Wm}^{-2}$ & 0.19 & 0.03 & 0.27 & Unlikely \\
\hline SRES B1 & 0.6 & 0.42 & 0.72 & Likely \\
\hline SRES A2 & 0.98 & 0.98 & 1.0 & Very likely \\
\hline
\end{tabular}


specific values (of costs) as the main outcome of our analysis, but general results that are robust with respect to a wide range of statistical and economic assumptions.

We will use three different damage cost functions. The following function $\mathrm{d}(t)$ is used in the DICE-99 model (Nordhaus and Boyer 2000; Warren et al. 2006):

$$
\mathrm{d}(t):=-0.0045 \cdot T(t)+0.0035 \cdot T^{2}(t), \quad \text { in }[\% \text { world GDP] }
$$

where $t$ is time, and $T$ is temperature increase (in $\left[{ }^{\circ} \mathrm{C}\right]$ ) relative to preindustrial time.

We also consider the damage cost functions

$$
\begin{aligned}
\mathrm{d}_{1}(t) & :=-0.0025 \cdot T(t)+0.00341 \cdot T^{2}(t) \\
\mathrm{d}_{2}(t) & :=0.0005 \cdot T(t)+0.00315 \cdot T^{2}(t)
\end{aligned}
$$

The function $\mathrm{d}_{(t)}$ is similar to the output-weighted damage cost function of the RICE99 model, and $\mathrm{d}_{2}(t)$ is similar to the population-weighted damage cost function of the RICE-99 model (Nordhaus and Boyer 2000; Warren et al. 2006). The left panel of Fig. 5 shows a plot of the three functions. The damage cost functions of the DICE/RICE model have since been updated (Nordhaus 2008), but the new functions lie within the range covered by $\mathrm{d}, \mathrm{d}_{1}$, and $\mathrm{d}_{2}$. Potential "catastrophic" losses in economic output due to irreversible changes in the climate system are not considered in our investigation.

Our sensitivity analysis also comprises the assumption on the discount rate for calculating future damage costs. At the high end, Nordhaus' earlier work (Nordhaus and Boyer 2000) uses a monetary discount rate of about 6\% per year, which is consistent with the rates of return paid by risky financial assets such as stocks. On the other hand, safe assets pay returns of just about $1 \%$. These may be appropriate for evaluating policies that are known to have a precautionary justification (Howarth 2003). For simplicity, here we present our results for two different discount rates, i.e. flat rates of $2 \%$ and $5 \%$. The right panel of Fig. 5 presents the world GDP assumed
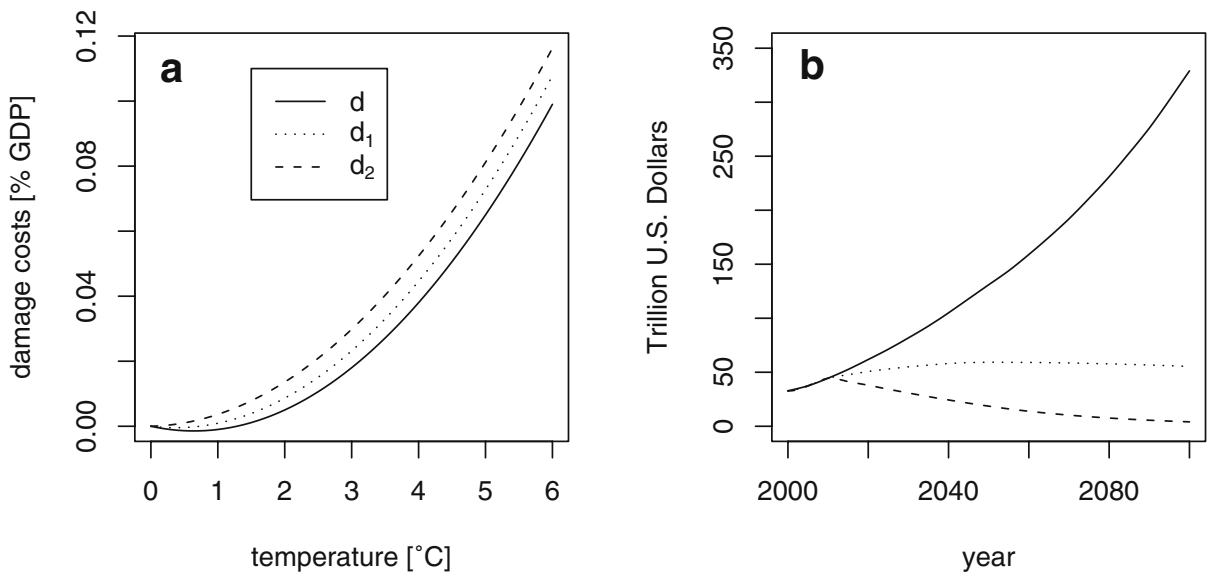

Fig. 5 a The three different damage cost functions used in the present analysis; $\mathbf{b}$ The world GDP assumed in the calculation of the damage costs with no discounting (solid line), discounting at $2 \%$ (dotted line), and discounting at $5 \%$ (dashed line) 
in the present study for the calculation of the damage costs with no discounting (solid line), discounting at 2\% (dotted line), and discounting at $5 \%$ (dashed line).

Figure 6 summarizes the results for three different scenarios: the IMAGE reference scenario (solid line), the IMAGE mitigation scenario that stabilizes radiative forcing at $4.5 \mathrm{~W} / \mathrm{m}^{2}$ (dotted line), and the scenario that stabilizes radiative forcing at $2.9 \mathrm{~W} / \mathrm{m}^{2}$ (dashed line). The probability density functions for damage costs are shown using the three damage cost functions $d$ (first row of the figure), $d_{1}$ (second row of the figure), and $\mathrm{d}_{2}$ (third row of the figure), and discount rates of $2 \%$ (first column) and $5 \%$ (second column). Note that cumulative damages over the whole time span were computed, discounted back to the year 2010. In the third column, the probability density functions of the coefficients $d$ (year2100) (first row), $d_{1}$ (year2100) (second row), and $d_{2}$ (year2100) (third row), calculated according to equations (8)(10), are presented.

The derived distributions for absolute (cumulative) damage costs depend heavily on the assumed discount rate, the chosen damage cost function, and the GDP trajectory of the scenario, and thus have to be interpreted with care. Nevertheless, three main observations can be made: (1) There is a clear distinction between the damage cost distributions of the different scenarios. However, the differences in the shape of the distributions are somewhat less pronounced than the differences in the distributions of 2100 temperature increase as a result of discounting (the smaller differences in early periods of time are given a higher weighting in the total). (2) The distributions are not well constrained from below, even for the IMAGE (non-intervention) reference scenario and the damage cost function $\mathrm{d}_{2}$. This again is an effect of discounting. (3) Distributions tend to become flatter, i.e. predictions more uncertain, when using damage cost functions that imply larger damage costs due to climate change, especially when considering scenarios that result in large temperature increases by the end of the 21st century. Larger damage costs at the end of the century (due to larger temperature increases) counteract the effect of discounting. Therefore, larger damage costs become more likely and the distributions spread out.

The third column of Fig. 6 allows for comparing damage costs in the year 2100 without considering the effect of discounting. Here the differences between the scenarios are most distinct. The damage coefficients measure the percent reduction in future (year 2100) economic output caused by climate change damages. These range from low $(0-4 \%)$ to moderate $(0-8 \%)$ depending on the damage function.

In summary, even when considering only uncertainties in climate system properties (as in the present study) damage costs are not well constrained, especially from below. However, in the case of stringent mitigation the risk of very high damage costs is reduced. The problem of discounting future damage costs as well as the appropriate choice of the damage cost function can be identified as the central issues. However, when comparing different mitigation options, discounting is of more central importance than the specific choice of a damage cost function.

Of course the question concerning the most adequate estimates of mitigation costs is also of major importance (Edenhofer et al. 2006), but this is not the focus of the present paper. Naturally, it would be desirable to compare damage costs with mitigation costs for the different mitigation scenarios. However, the Integrated Assessment Model IMAGE, which was used to develop the scenarios and estimate the corresponding mitigation costs, only calculates changes in energy technologies and associated costs in the energy system, but not macro-economic costs (i.e. GDP 


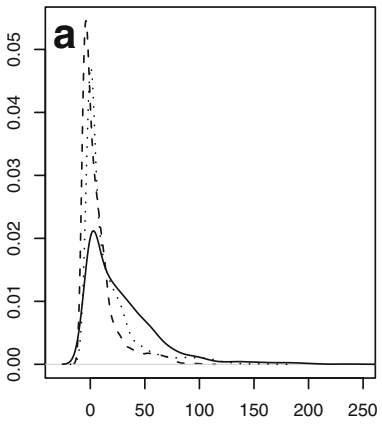

damage costs [Trillion U.S. Dollars]

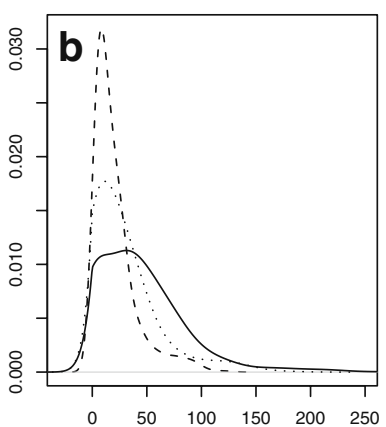

damage costs [Trillion U.S. Dollars]

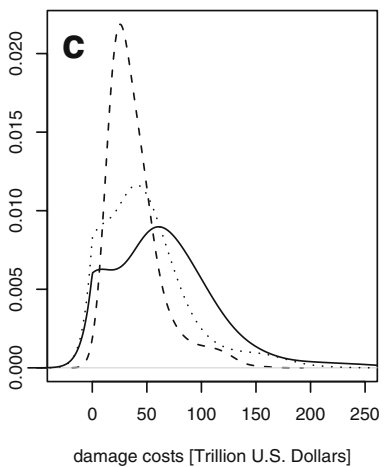

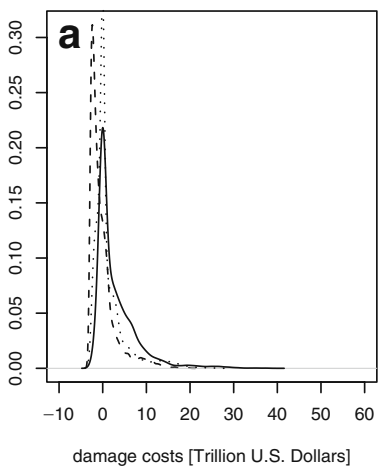

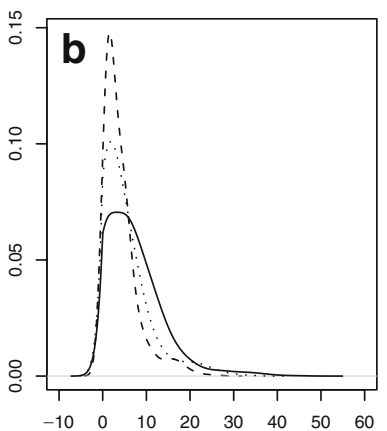

damage costs [Trillion U.S. Dollars]

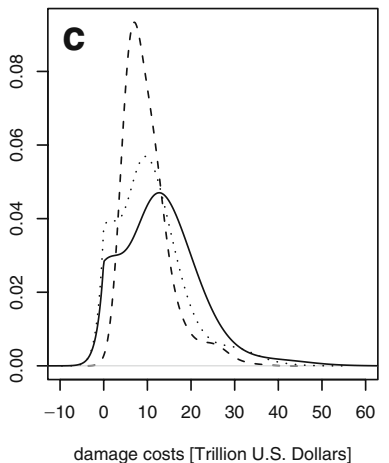

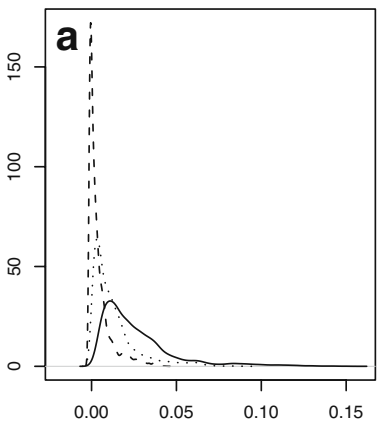

coefficient year $2100[\%$ world GDP]

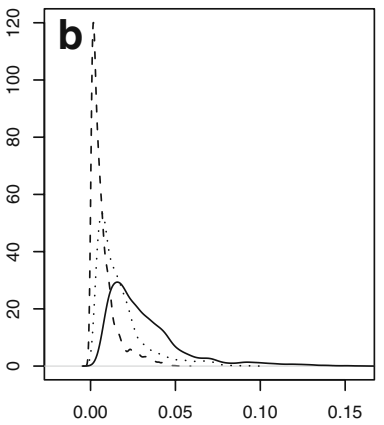

coefficient year $2100[\%$ world GDP]

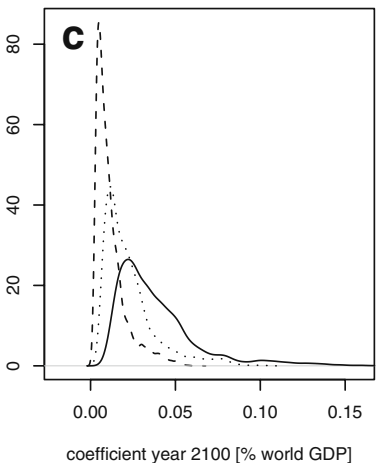

Fig. 6 Net present value of (cumulative) damage costs until year 2100 for different scenarios in trillion U.S. Dollars 1995, discounted to year 2010 with a discount rate of $2 \%$ (left column) and $5 \%$ (mid column), respectively, using damage cost functions $\mathrm{d}(\mathbf{a}), \mathrm{d}_{1}(\mathbf{b})$, and $\mathrm{d}_{2}$ (c). Solid lines refer to the IMAGE reference scenario, dotted lines to the IMAGE mitigation scenario that stabilizes radiative forcing at $4.5 \mathrm{~W} / \mathrm{m}^{2}$, and dashed lines to the IMAGE mitigation scenario that stabilizes radiative forcing at $2.9 \mathrm{~W} / \mathrm{m}^{2}$. In the right column the probability density functions of the coefficients $d$ (year2100) (row $a), d_{1}$ (year2100) (row b), and $d_{2}$ (year2100) (row c), calculated according to equations (8)-(10), are presented

losses). The mitigation costs calculated by IMAGE should thus be seen as annual additional investments for mitigation, mostly into the energy system (which can spur investments and development in other sectors of the economy not considered by 
the energy system model), and not as GDP losses as in the case of macro-economic models (such as DICE/RICE models). Therefore, damage costs calculated by our damage cost functions can not be directly compared to mitigation costs that are estimated using IMAGE.

\section{Discussion and conclusions}

We present probabilistic temperature projections based on two SRES emission scenarios, an IMAGE reference emission scenario and five IMAGE mitigation emission scenarios, aimed at stabilizing radiative forcing, using a climate model of intermediate complexity. Importantly, all scenarios are multi-gas scenarios in that they also consider contributions to radiative forcing from non- $\mathrm{CO}_{2}$ greenhouse gases and other radiative agents apart from $\mathrm{CO}_{2}$. While projections for the first half of the 21st century are rather insensitive to the choice of scenario for a given family of scenarios, the scenarios diverge markedly with respect to both projected temperature increase and associated uncertainty by the year 2100. Thus, given current knowledge about climate model parameters as constrained by historical observations, some mitigation scenarios are much riskier than others. Explicit consideration of this risk has important implications for the required robustness of planned adaptation strategies (Heinz Center 2007).

For the SRES scenarios, our results are in broad agreement with earlier studies (see Knutti et al. (2008) for an overview). The heavy tails towards high warming appear to be a bit more pronounced than in some other studies, in particular for the lower scenarios, while the distributions for the reference and SRES A2 case, for example, are more symmetric. The apparent heavy tails in the estimated probability density functions of projected temperature increase in the present work are mainly a consequence of the tail in the propagated distribution of climate sensitivity and are due to two reasons. First, the propagated probability distribution for climate sensitivity in our case is on the low end compared to other published estimates. Therefore our model may be closer to equilibrium than others in 2100 and the imprint of the heavy tail in climate sensitivity is clearer. Second, some of the scenarios considered essentially stabilize climate by the year 2100, so for those cases the distributions for temperature must be similar to the distribution of climate sensitivity. Figure $3 \mathrm{~b}$ confirms that the low scenarios have a more pronounced long tail, whereas the SRES A2 case, for instance, is more symmetric, in agreement with earlier studies which mostly focused on scenarios with increasing forcing (see Knutti et al. 2008). Both the somewhat lower sensitivity estimate and the stabilizing forcing tend to make the transient response more similar to the equilibrium response.

In addition, some earlier studies (e.g. Stott et al. 2006; Harris et al. 2006; Furrer et al. 2007) did not account for uncertainties in the carbon cycle climate feedback. The latter affects the high end of the distribution much more strongly than the low end as already shown (Knutti et al. 2003, Fig. 7d) using a different statistical framework, different prior distributions, and different ocean mixing parameterizations. The heavy tails towards high warming found in this study are therefore a combination of stabilizing climate (a feature of the scenarios), a lower climate sensitivity estimate compared to other estimates (a result of the statistical assumptions and the observational constraints) and an amplification at high warming caused by the 
carbon cycle-climate feedback (an effect often ignored so far) rather than the effect of prior assumptions on parameters other than climate sensitivity, or the statistical framework.

In the Bayesian framework, predictive probabilities may be sensitive to the choice of prior distributions. To assess how well our projections are constrained depending on different assumptions on the priors for climate seinsitivity, we evaluated a broad set of such distributions including the uniform prior. The resulting upper and lower probabilities for a temperature increase of more than $2^{\circ} \mathrm{C}$ in the year 2100 show spans that are approximately consistent with those used in the IPCC terminology. Extreme probabilities (i.e. "very likely", "very unlikely") have spans of less than $10 \%$, while those closer to the middle have spans of about $30 \%$. Thus, the IPCC terminology seems to appropriately represent the degree of "imprecision" that is currently present in probabilistic projections due to alternative possible priors. However, quantitative descriptions such as those given in our Table 3 , have the potential to be more informative, especially for scenarios with probabilities that cross the thresholds used in the definitions of the IPCC terminology (e.g. Level $4.5 \mathrm{Wm}^{-2}$ ).

Our projections are quite robust with respect to prior assumptions on climate sensitivity. Only the most stringent mitigation scenarios are considered "unlikely" to exceed a temperature increase of $2^{\circ} \mathrm{C}$ by the end of the 21 st century. These stringent mitigation scenarios are overshoot scenarios that peak radiative forcing in the mid 21st century and show a decrease afterwards, consistent with findings of Meinshausen (2005), Meinshausen et al. (2009), and Allen et al. (2009). Our results also suggest that the question of whether it is important to consider the uncertainty in climate sensitivity in impact studies depends on the chosen time horizon as well as the specific decision problem under investigation (Frame et al. 2006).

Going one step further, we also calculate probability distributions of damage costs for the different scenarios assuming a range of damage cost functions. Moreover, the sensitivity of these distributions with respect to the assumed discount rate is investigated. Absolute values of damage costs heavily depend on the chosen damage cost function and discount rate. For the decision problem of what stabilization path should be followed in the future, discounting is the more fundamental issue.

Relatively high discount rates (e.g. 5.5\% of Nordhaus 2007) are often justified by observed market rates of return. However, low discount rates (e.g. 1.4\% of Stern (2006) which sets the discount rate almost at the long-term per capita growth rate of consumption) can be justified based on moral arguments concerning intergenerational equity and responsibility. Some have argued for a strongly decreasing discount rate over time (e.g. Weitzman 2001). One caveat is that some of these arguments cast doubt on the use of present-value calculations in justifying particular climate stabilization goals. Therefore, while we treat the discount rate in our analysis as if it were an uncertain quantity, in reality it is a normative choice about how to distribute the burden and benefits of climate change policy over time (see Howarth (2005) and Odling-Smee (2007) for a detailed discussion), and hence a policy choice. We hope that our results can shed some light on how the implications of this choice interact with uncertainties in 21 st century temperature projections and the anticipated pattern of damage costs.

Various tools can be used to evaluate climate targets. These include both risk based approaches (description of potential impacts as a function of climate change) and cost-benefit analyses (a monetary assessment of costs and benefits of various policies). Recently, people have started a lively debate on the strengths and 
weaknessess of cost-benefit analyses in the context of climate change (Weitzman 2009). Part of this are various problems with the valuation of climate change. Contentious issues include: valuation of damages to non-marketed goods and services, aggregation of damages over the globe, huge uncertainties in the actual future development of the world etc. More importantly, traditional cost-benefit analysis tends to ignore the large uncertainties involved in climate outcomes. In specific decision-making contexts, the presence of uncertainty implies that approaches that focus on robust strategies are preferable to adaptation designs that are based on a single projected climate condition (Hallegate 2009). For example, land-use policies that aim at limiting urbanization in flood-prone areas reduce disaster losses in the present climate. Likewise, policies that foster energy efficiency are beneficial in a wide range of respects. Under climate change conditions such measures might become even more desirable.

The analysis of a comprehensive range of possible scenarios in combination with probabilistic approaches as presented in this paper can contribute to improved tools to support the decision making process.

Acknowledgements The authors acknowledge support by the Swiss National Science Foundation. Although MEB and RBH have been funded in part by the United States Environmental Protection Agency through grant R833666, the research described in this paper has not been subjected to the Agency's peer and policy review and therefore does not necessarily reflect the views of the Agency and no official endorsement should be inferred.

\section{References}

Allen MR, Frame DJ, Huntingford C, Jones CD, Lowe JA, Meinshausen M, Meinshausen N (2009) Warming caused by cumulative carbon emissions towards the trillionth ton. Nature 458:11631166

Ammann CM, Meehl GA, Washington WM, Zender CS (2003) A monthly and latitudinally varying volcanic forcing dataset in simulations of 20th century climate. Geophys Res Lett 30:1657. doi:10.1029/2003GL016875

Bard E, Raisbeck G, Yiou F, Jouzel J (2000) Solar irradiance during the last 1200 years based on cosmogenic nuclides. Tellus B 52:985-992

Berger J (1984) The robust Bayesian viewpoint. In: Kadane J (ed) Robustness in Bayesian statistics. North-Holland, Amsterdam

Berger J (1994) An overview of robust Bayesian analysis. Test 3:5-124

Camerer C, Weber M (1992) Recent developments in modeling preferences: uncertainty and ambiguity. J Risk Uncertain 5:325-370

Commission of the European Communities (2007) Limiting global climate change to 2 degrees Celsius. The way ahead for 2020 and beyound. Communication from the commission to the council, the European parliament, the economic and social sommittee and the committee of the regions, Brusssels

Crowley TJ (2000) Causes of climate change over the past 1000 years. Science 289:270-277

den Elzen MGJ, Lucas P (2003) FAIR 2.0-a decision support tool to assess the environmental and economic consequebces of future climate regimes. National Institute of Public Health and the Environment, Bilthoven

den Elzen MGJ, Meinshausen M, van Vuuren DP (2007) Multi-gas emission envelopes to meet greenhouse gas concentration targets: costs versus certainty of limiting temperature increase. Glob Environ Change 17:260-280

De Robertis L, Hartigan JA (1981) Bayesian inference using intervals of measures. Ann Statist 9:235-244

Dessai S, Hulme M (2007) Assessing the robustness of adaptation decisions to climate change uncertainties: a case study on water resources management in the East of England. Glob Environ Change 17:59-72 
Edenhofer O, Carraro C, Koehler J, Grubb M (eds) (2006) Endogenous technological change and the economics of atmospheric stabilization. A special issue of the Energy Journal 27, International Association of Energy Economics

Etheridge DM, Steele LP, Langenfelds RL, Francey RJ, Barnola JM, Morgan VI (1996) Natural and anthropogenic changes in atmospheric $\mathrm{CO}_{2}$ over the last 1000 years from air in Antarctic ice firn. J Geophys Res 101:4115-4128

Forest CE, Stone P, Sokolov A (2006) Estimated PDFs of climate system properties including natural and anthropogenic forcings. Geophys Res Lett 33. doi:10.1029/2005GL023977

Forster P, Ramaswamy V, Artaxo P, Berntsen T, Betts R, Fahey DW, Haywood J, Lean J, Lowe DC, Myhre G, Nganga J, Prinn R, Raga G, Schulz M, Van Dorland R (2007) Changes in atmospheric constituents and in radiative forcing. In: Solomon, S, Qin D, Manning M, Chen Z, Marquis M, Averyt KB, Tignor M, Miller HL (eds) Climate change 2007: the physical science basis. Contribution of working group I to the fourth assessment report of the intergovernmental panel on climate change. Cambridge University Press, Cambridge, pp 129-234

Frame DJ, Stone DA, Stott PA, Allen MR (2006) Alternatives to stabilization scenarios. Geophys Res Lett 33:L14707. doi:10.1029/2006GL025801

Friedlingstein P, Cox P, Betts R, Bopp L, Von Bloh W, Brovkin V, Cadule P, Doney S, Eby M, Fung I, Bala G, John J, Jones C, Joos F, Kato T, Kawamiya M, Knorr W, Lindsay K, Matthews HD, Raddatz T, Rayner P, Reick C, Roeckner E, Schnitzler KG, Schnur R, Strassmann K, Weaver AJ, Yoshikawa C, Zeng N (2006) Climate-carbon cycle feedback analysis: results from the C4MIP model intercomparison. J Climate 19:3337-3353

Furrer R, Knutti R, Sain SR, Nychka D, Meehl GA (2007) Spatial patterns of probabilistic temperature change projections from a multivariate Bayesian analysis. Geophys Res Lett 34:L06711. doi:10.1029/2006GL027754

Gregory JM, Jones CD, Cadule P, Friedlingstein P (2009) Quantifying carbon-cycle feedbacks. J Climate 22:5232-5250

Hallegatte S (2009) Strategies to adapt to an uncertain climate change. Glob Environ Change 19:240-247

Haney RL (1971) Surface thermal boundary condition for ocean general circulation models. J Phys Oceanogr 1:241-248

Harris G, Sexton DMH, Booth BBB, Collins M, Murphy JM, Webb MJ (2006) Frequency distributions of transient regional climate change from perturbed physics ensembles of general circulation model simulations. Clim Dyn 27:357-375

Heinz Center (2007) A survey of climate change adaptation planning, the H. John Heinz III Center for Science, Economics, and the Environment, Washington, DC

Howarth RB (2003) Discounting and uncertainty in climate change policy analysis. Land Econ 79:369-381

Howarth RB (2005) Against high discount rates. In: Sinnott-Armstrong W, Howarth RB (eds) Perspectives on climate change: science, economics, politics, ethics. Elsevier, Amsterdam

IPCC (2001) Climate change 2001: the scientific basis. In: Houghton JT et al (eds) Contribution of working group I to the third assessment report of the intergovernmental panel on climate change. Cambridge University Press, Cambridge

IPCC (2007) Climate change 2007: the physical science basis. In: Solomon S et al (eds) Contribution of working group I to the fourth assessment report of the intergovernmental panel on climate change. Cambridge University Press, Cambridge

Isaaks EH, Srivastava RM (1989) An introduction to applied geostatistics. Oxford University Press, Oxford

Jones PD, Moberg A (2003) Hemispheric and large-scale air temperature variations: an extensive revision and an update to 2001. J Climate 16:206-223. See also http://www.met-office. gov.uk/research/hadleycentre/CR_data/Annual/land+sst_web.txt

Joos F, Plattner GK, Stocker TF, Marchal O, Schmittner A (1999) Global warming and marine carbon cycle feedbacks on future atmospheric $\mathrm{CO}_{2}$. Science 284:464-467

Joos F, Prentice IC, Sitch S, Meyer R, Hooss G, Plattner GK, Gerber S, Hasselmann K (2001) Global warming feedbacks on terrestrial carbon uptake under the IPCC emission scenarios. Glob Biogeochem Cycles 15:891-907

Keeling CD, Whorf TP (2005) Atmospheric $\mathrm{CO}_{2}$ records from sites in the SIO air sampling network. In: Trends: a compendium of data on global change. Carbon Dioxide Information Center, Oak Ridge National Laboratory, Oak Ridge

Knutti R, Stocker TF, Wright DG (2000) The effects of subgrid-scale parameterizations in a zonally averaged ocean model. J Phys Oceanogr 30:2738-2752 
Knutti R, Stocker TF, Joos F, Plattner GK (2002) Constraints on radiative forcing and future climate change from observations and climate model ensembles. Nature 416:719-723

Knutti R, Stocker TF, Joos F, Plattner GK (2003) Probabilistic climate change projections using neural networks. Clim Dyn 21:257-272

Knutti R, Joos F, Müller SA, Plattner GK, Stocker TF (2005) Probabilistic climate change projections for $\mathrm{CO}_{2}$ stabilization profiles. Geophy Res Lett 32:L20707. doi:10.1029/2005GL0232294

Knutti R, Allen MR, Friedlingstein P, Gregory JM, Hegerl GC, Meehl GA, Meinshausen M, Murphy JM, Plattner G.-K., Raper SCB, Stocker TF, Stott PA, Teng H, Wigley TML (2008) A review of uncertainties in in global temperature projections over the twenty-first century. J Climate 21:2651-2663

Knutti R, Tomassini L (2008) Constraints on the transient climate response from observed global temperature and ocean heat uptake. Geophys Res Lett 35:L09701. doi:10.1029/2007GL032904

Knutti R, Hegerl G (2008) The equilibrium sensitivity of the Earth's temperature to radiation changes. Nature Geosci 1:735-743

Lempert RJ, Schlesinger ME (2000) Robust strategies for abating climate change. Clim Change 45:387-401

Levitus S, Antonov J, Boyer T (2005) Warming of the world ocean, 1955-2003. Geophys Res Lett 32:L02604. See also http:/www.nodc.noaa.gov/DATA_ANALYSIS/temp/basin/hc1yrwO-700m.dat

Meinshausen M (2005) On the risk of overshooting $2{ }^{\circ} \mathrm{C}$. In: Schellnhuber JS et al (eds) Avoiding dangerous climate change. Cambridge University Press, Cambridge

Meinshausen M, Meinshausen N, Hare W, Raper SCB, Frieler K, Knutti R, Frame DJ, Allen MR (2009) Greenhouse emission targets for limiting global warming to $2{ }^{\circ} \mathrm{C}$. Nature 458:1158-1163

MNP (2006) Integrated modelling of global environmental change. An overview of IMAGE 2.4. In: Bouwman AF, Kram T, Klein Goldewijk K (eds) Netherlands Environmental Assessment Agency Report 500110002/2006, Bilthoven

Morgan MG, Keith DW (1995) Subjective judgments by climate experts. Environ Sci Technol 29:468-476

Murphy JM, Sexton DMH, Barnett DN, Jones GS, Webb MJ, Collins M, Stainforth DA (2004) Quantification of modelling uncertainties in a large ensemble of climate change simulations. Nature 430:768-772

Myhre G, Highwood EJ, Shine KP, Stordal F (1998) New estimates of radiative forcing due to well mixed greenhouse gases. Geophys Res Lett 25:2715-2718

Nakicenovic N, Alcamo J, Davis G, de Vries B, Fenham J, Gaffin S, Gregory K, Grubler A, Jung TY, Kram T, La Rovere EL, Michaelis L, Mori S, Morita T, Pepper W, Pitcher H, Price L, Riahi K, Roehrl A, Rogner HH, Sankovski A, Schlesinger M, Shukla P, Smith S, Swart R, van Rooijen S, Victor N, Dadi Z (2000) Special report on emissions scenarios. Working group III, intergovernmental panel on climate change (IPCC). Cambridge University Press, Cambridge

Nordhaus WD, Boyer J (2000) Warming the world. MIT, Cambridge

Nordhaus WD (2007) A review of the Stern review on the economics of climate change. J Econ Lit 45:686-702

Nordhaus WD (2008) A question of balance: economic modeling of global warming. Yale University Press, New Haven

Odling-Smee L (2007) What price a cooler future? Nature 445:582-583

Plattner GK, Joos F, Stocker TF, Marchal O (2001) Feedback mechanism and sensitivities of ocean carbon uptake under global warming. Tellus 53B:564-592

Plattner GK, Knutti R, Joos F, Stocker TF, von Bloh W, Brovkin V, Cameron D, Driesschaert E, Dutkiewicz S, Eby M, Edwards NR, Fichefet T, Hargreaves JC, Jones CD, Loutre MF, Matthews HD, Mouchet A, Mueller SA, Nawrath S, Price A, Sokolov A, Strassmann KM, Weaver AJ (2008) Long-term climate commitments projected with climate-carbon cycle models. J Climate 21:2721-2751

Schmittner A, Stocker TF (1999) The stability of the thermohaline circulation in global warming experiments. J Climate 12:1117-1133

Siegenthaler U, Monnin E, Kawamura K, Spahni R, Schwander J, Stauffer B, Stocker TF, Barnola JM, Fischer H (2005) Supporting evidence from EPICA Dronning Maud Land ice core for atmospheric $\mathrm{CO}_{2}$ changes during the past millenium. Tellus 57B:51-57

Stainforth DA, Aina T, Christensen C, Collins M, Faull N, Frame DJ, Kettleborough JA, Knight S, Martin A, Murphy JM, Piani C, Sexton D, Smith LA, Spicer RA, Thorpe AJ, Allen MR (2005) Uncertainty in predictions of the climate response to rising levels of greenhouse gases. Nature 433:403-406 
Stern DI (2005) Global sulfur emissions from 1850 to 2000. Chemosphere 58:163-172

Stern N (2006) The economics of climate change, the Stern review. Cambridge University Press, Cambridge

Stocker TF, Wright DG (1991) A zonally averaged model for the thermohaline circulation. Part II: interocean exchanges in the Pacific-Atlantic basin system. J Phys Oceanogr 21:1725-1739

Stocker TF, Wright DG, Mysak LA (1992) A zonally averaged, coupled ocean-atmosphere model for paleoclimate studies. J Climate 5:773-797

Stott PA, Kettleborough JA (2002) Origins and estimates of uncertainty in predictions of twenty-first century temperature rise. Nature 416:723-726

Stott PA, Mitchell JFB, Allen MR, Delworth TL, Gregory JM, Meehl GA, Santer BD (2006) Observational constraints on past attributable warming and predictions of future global warming. J Climate 19:3055-3069

Tebaldi C, Smith RL, Nychka D, Mearns LO (2005) Quantifying uncertainty in projections of regional climate change: a Bayesian approach to the analysis of multi-model ensembles. J Climate 18:1524-1540

Tomassini L, Reichert P, Knutti R, Stocker TF, Borsuk ME (2007) Robust Bayesian uncertainty analysis of climate system properties using Markov chain Monte Carlo methods. J Climate 20:1239-1254

van Vuuren DP (2007) Energy systems and climate policy: long-term scenarios for an uncertain future. Dissertation, Utrecht University, Utrecht

van Vuuren DP, Eickhout B, Lucas PL, den Elzen MGJ (2006) Long-term multi-gas scenarios to stabilise radiative forcing - exploring costs and benefits within an integrated assessment framework. Energy J 3:201-234 (special issue)

van Vuuren DP, den Elzen MGJ, Lucas P, Eickhout BE, Strengers BJ, van Ruijven V, Wonink S, van Houdt R (2007) Stabilizing greenhouse gas concentrations at low levels: an assessment of reduction strategies and costs. Clim Change 81:119-159

Wang YM, Lean JL, Sheeley NL Jr (2005) Modeling the sun's magnetic field and irradiance since 1713. Astrophys J 625:522-538

Warren R, Hope C, Mastrandrea M, Tol R, Adger N, Lorenzoni I (2006) Spotlighting impacts functions in integrated assessment, research report prepared for the Stern review on the economics of climate change. Tyndall Centre for Climate Change Research, Working Paper 91

Wasserman L, Kadane JB (1992) Computing bounds on expectations. J Am Stat Assoc 87:516-522

Webster M (2003) Communicating climate change uncertainty to policy-makers and the public. Clim Change 61:1-8

Weitzman ML (2001) Gamma discounting. Am Econ Rev 91:261-271

Weitzman ML (2009) On modeling and interpreting the economics of catastrophic climate change. Rev Econ Stat 91:1-19

Weyant JP, de la Chesnaye FC, Blanford GJ (2006) An overview of EMF-21: multigas mitigation and climate change. Energy $\mathrm{J}$ (special issue 3)

Wigley TML, Raper SCB (2001) Interpretation of high projections for global-mean warming. Science 293:451-454

Wright DG, Stocker TF (1991) A zonally averaged ocean model for the thermohaline circulation, Part I: model development and flow dynamics. J Phys Oceanogr 21:1713-1724 